\title{
AVALIAÇÃO DO RISCO A CONTAMINAÇÃO NATURAL DOS AQUÍFEROS NO MUNICÍPIO DE CAÇAPAVA DO SUL-RS
}

Ladislau Aparecido da Costa Arruda Junior - ladisarrudajr@ gmail.com Universidade Federal do Pampa - UNIPAMPA

Maximilian Fries - maximilianfries@ unipampa.edu.br

Universidade Federal do Pampa - UNIPAMPA

Jauana Marilise do Nascimento Riegel - riegel.jauana@ gmail.com

Universidade Federal do Pampa - UNIPAMPA 


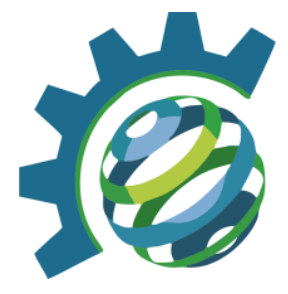

\section{RESUMO}

A região do pampa no Estado do Rio Grande do Sul - Brasil possui como característica hidrogeológica, aquíferos de baixo acúmulo e vazão. Este trabalho tem como principal proposta a confecção de mapa temático de vulnerabilidade de aquífero no município de Caçapava do Sul utilizando o método GOD. A área de estudo localiza-se no encontro de três importantes bacias hidrográficas e a metodologia adotada baseia-se na coleta de informações pré-existentes onde foi gerado um banco de dados dos poços tubulares cadastrados no município. A integração de dados permitiu a geração de um mapa de avaliação de risco. Domínios de Insignificante, Baixo e Médio graus de vulnerabilidade foram definidos e os resultados oferecem uma abordagem de fácil acesso e utilização por profissionais e gestores. Além disso fornecem um diagnóstico inicial e importantes subsídios para formular hipóteses e futuros estudos no aprimoramento da base de dados atual.

Palavras-Chave: Método GOD, Região do Pampa, Recurso Hídricos.

\section{INTRODUÇÃO/ OBJETIVO}

A água subterrânea é um recurso natural indispensável para a manutenção dos ecossistemas, subsistência da humanidade e meio ambiente. Apresenta grande importância na retenção de umidade no solo, garantindo um fluxo de base dos cursos de água, respondendo por sua perenizarão em tempos de estiagens, sendo vital para a sobrevivência de todos os seres vivos. A fim de sanar as deficiências e aumento da demanda no abastecimento público, estes recursos estão sendo cada vez mais explorados. Este aumento da exploração sem estudos prévios e de forma indiscriminada torna esses recursos susceptíveis a agentes externos como saneamento básico precário, indústrias, postos de gasolina, cemitérios, aterros sanitários e lixões.

Estes riscos potenciais de contaminação do aquífero são representados pelos resíduos, tanto sólidos como líquidos gerados através das atividades antrópicas visto que, na maior parte dos casos, a água subterrânea é menos contaminada do que a superficial, uma vez que se encontra protegida da contaminação à superfície proveniente dos solos e da cobertura rochosa (PROSPECTO, 2007). Junto a estes problemas de contaminação existem os problemas relacionados à exploração excessiva dos recursos subterrâneos, a ocupação irregular do solo e a não conformidade quanto as normas legais de utilização destes recursos. 

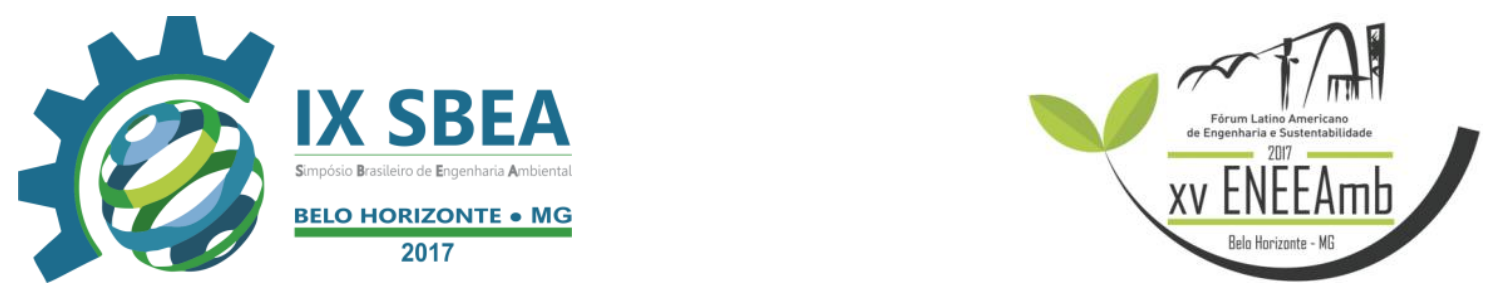

Tendo em vista que os contaminantes em sua maioria podem ser oriundos de: nutrientes, metais pesados, micro-organismos, patógenos (SELLER e CANTER 1980; LE GRAND, 1983; CARTER et. al., 1987). Desta forma, faz-se necessário, segundo (AMARAL et al., 2003), a tomada de medidas de proteção especial para os poços e nascentes, sejam públicos ou privados. Ainda, de acordo com (FOSTER et al. 2006), é importante considerar que a água subterrânea é um recurso natural vital para o abastecimento econômico e seguro nos meios urbano e rural.

Portanto, prover a captação e fornecer água de qualidade para o abastecimento é de fundamental importância no desenvolvimento socioeconômico das cidades situadas na região do pampa. Considerando esses fatores, uma avaliação da vulnerabilidade natural à contaminação é importante na análise de aquíferos. Atua de forma diagnóstica, a partir das características destes, avaliando sua capacidade de ser afetado por uma carga contaminante imposta.

Análises usando-se o estudo do mapeamento da vulnerabilidade natural do aquífero à contaminação já vem sendo realizados largamente no mundo todo (AFONSO et al., 2008; ALMARSI, 2008; AWAWDEH e NAWAFLEH, 2008; THIRUMALAIVASAN e KARMEGAM, 2011) e no Brasil (HIRATA et. al., 1991; CUTRIM e CAMPOS, 2010; BARBOSA et al., 2007), associando-se as áreas de potencial poluidor segundo os licenciamentos cadastrados no site da Fundação Estadual de Proteção Ambiental - RS (FEPAM) servem, também, como subsídios técnicos para a gestão dos recursos hídricos subterrâneos do município e uso e ocupação do solo.

Este trabalho tem como principal objetivo um estudo da vulnerabilidade através da técnica desenvolvida por FOSTER e HIRATA (1987) denominada de GOD (G - Grau de confinamento hidráulico da água subterrânealaquífero; $\mathrm{O}$ - Ocorrência de extratos de cobertura; D - Distância/Profundidade até o lençol freático), na prevenção da contaminação dos aquíferos no município de Caçapava do Sul, Estado do Rio Grande do Sul (Figura 1). 


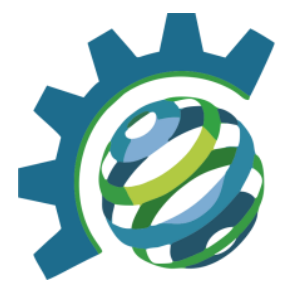

O município possui uma área total de $3.047 .113 \mathrm{~km}^{2}$ e população de 34.654 (IBGE 2015). Apresenta uma densidade demográfica de 11,06 hab/ $\mathrm{km}^{2}$. A renda per capta é $18.021,00$ (IBGE 2013) e a cidade pertence a macrorregião sul do pais e mesorregião do Sudeste RioGrandense, inserida na microrregião das Serras de Sudeste.

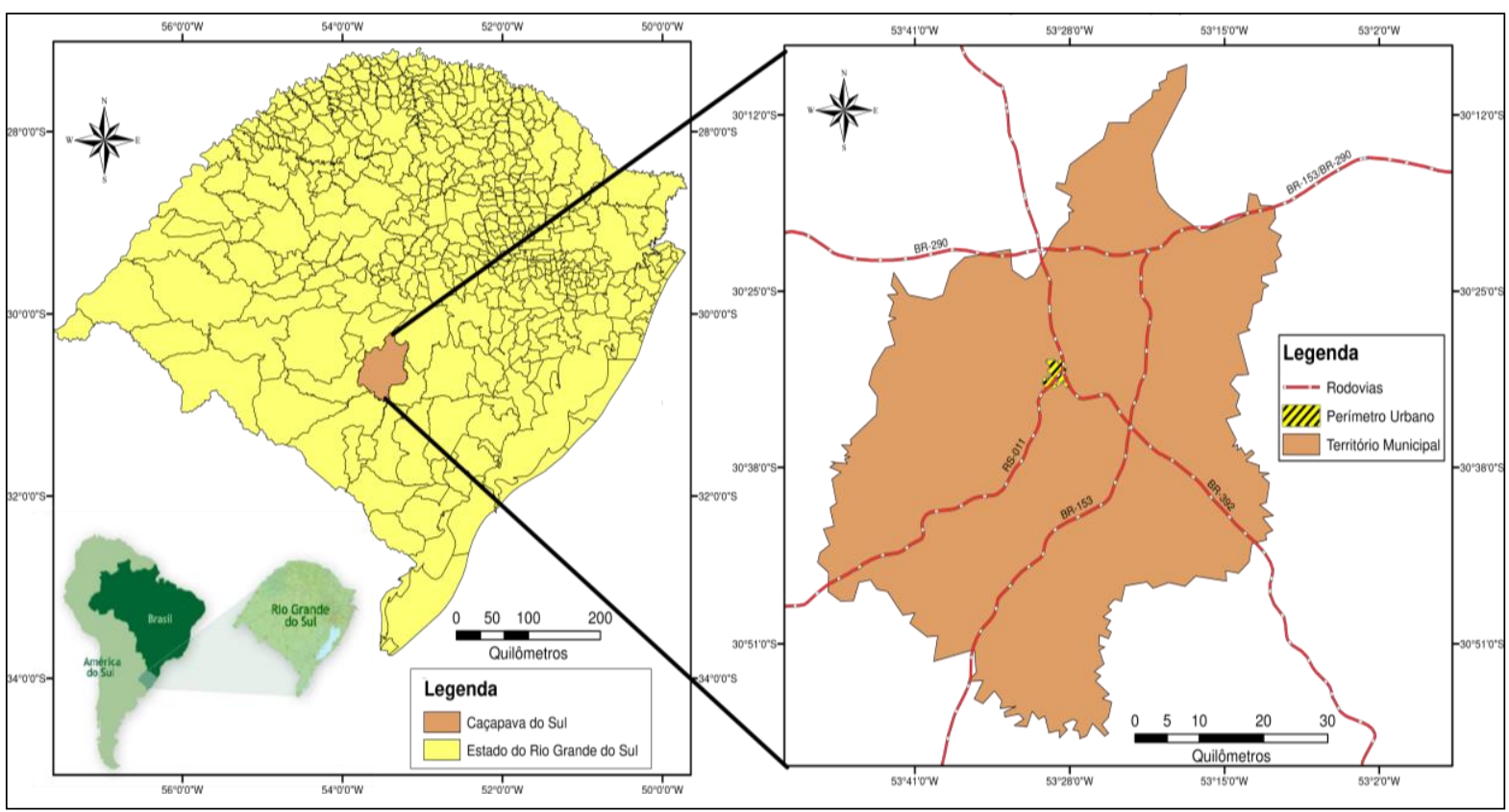

Figura 1 - Mapa de localização, principais rodovias e acessos da área de estudo.

\section{METODOLOGIA}

Para a avaliação do índice de vulnerabilidade através da técnica GOD é considerado o nível estático do aquífero, o meio onde encontra-se do aquífero e as litologias. Como todos os parâmetros possuem o mesmo grau de importância, pode-se determinar o Índice de Vulnerabilidade segundo a definição de FOSTER et al. (2006), onde TAVARES et al. (2009) estabelece etapas para a determinação do indie de vulnerabilidade:

i) Grau de confinamento da água subterrânea;

ii) Ocorrência de estratos de cobertura;

iii) Distância da água subterrânea à superfície do terreno;

As três etapas indicam o índice de vulnerabilidade dos aquíferos em insignificante $(0$ a 0,1$)$; baixo $(0,1$ a 0,3$)$; médio $(0,3$ a 0,5$)$, alto $(0,5$ a 0,7$)$ e extremo $(0,7$ a 1,0$)$. 

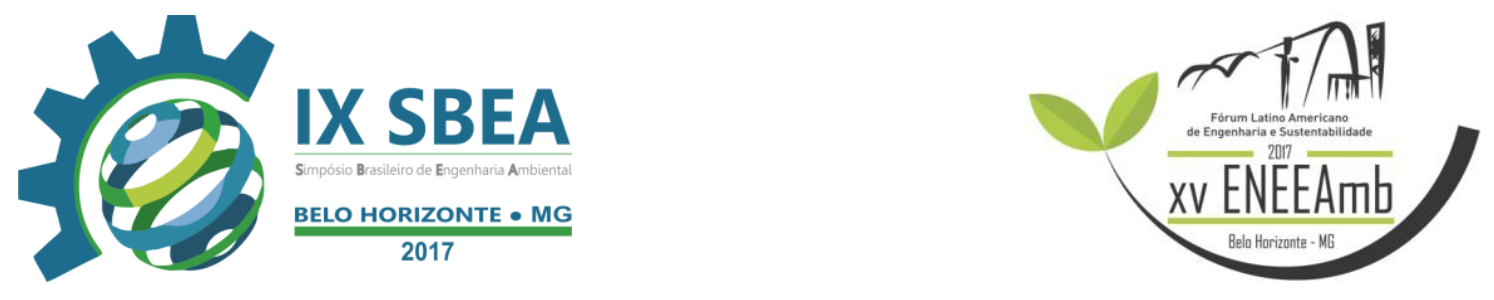

A utilização desta técnica, além de proporcionar a determinação da vulnerabilidade natural das águas subterrâneas do município gerou, secundariamente, através da sistemática adotada os seguintes resultados:

a) Quantidade de poços de águas subterrânea existentes na região e suas respectivas condições de funcionamento e atividades potencialmente poluidoras do município das águas subterrâneas;

b) Mapas temático com dados de vulnerabilidade natural de contaminação dos aquíferos e potencial poluidor dos principais empreendimentos no município.

\section{a) Base de dados}

Inicialmente, para a criação da base de dados, foi utilizado:

- Dados do Sistema de Informações de Águas Subterrâneas (SIAGAS), (CPRM 2016);

- Dados dos 585 licenciamentos ambientais cadastrados na Fundação Estadual de Proteção Ambiental (FEPAM, 2016).

\section{b) Determinação do índice de vulnerabilidade e espacialização dos dados - mapas temáticos}

O banco de dados integrado foi gerado em software especifico para dados em ambiente SIG. Uma planilha com fórmula pré-programada que multiplica os valores estabelecidos para cada parâmetro, gerando automaticamente o resultado final foi aplicada.

Estes resultados, inseridos em planilha própria do software Surfer v12 da GOLDENSOFTWARE (2012) foram interpolados nas áreas com ausência de dados amostrados. Para interpolação utilizou-se o método da Krigagem. De acordo com ISAAKS E SRIVASTAVA (1989), consiste na análise de um semivariograma experimental, fornecendo, em média, estimativas não tendenciosas e com variância mínima.

Os produtos gerados pela interpolação serviram para a geração dos mapas espacializados e blocos diagrama. Tanto para georreferenciamento como para a geração dos mapas de vulnerabilidade, foi empregado o sistema de coordenadas Universal Transversa de Mercator (UTM) utilizando Datum Horizontal SIRGAS 2000, zona 22 sul. 


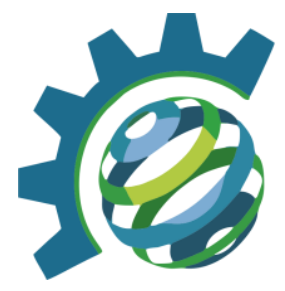

Todos os processamentos, análises e geração de mapas foram realizados utilizando-se softwares licenciados e de propriedade da Universidade Federal do Pampa - Campus Caçapava do Sul, Rio Grande do Sul.

\section{RESULTADOS E DISCUSSÃO}

Por meio da análise dos atributos i) cota do terreno; ii) geologia da área e iii) nível estático. O índice GOD final foi obtido e possibilitou a identificação de áreas mais sensíveis à contaminação e áreas com grande risco de contaminação.

Conforme apresentado na Tabela 1 , as avaliações de vulnerabilidade variam de insignificante a média.

\begin{tabular}{|c|c|c|c|c|c|c|}
\hline $\begin{array}{c}\text { Este } \\
\text { (UTM) }\end{array}$ & $\begin{array}{l}\text { Norte } \\
\text { (UTM) }\end{array}$ & $\begin{array}{l}\text { Código } \\
\text { do Poço } \\
(43000+)\end{array}$ & $\begin{array}{c}\text { Cota do } \\
\text { Terreno } \\
\text { (m) }\end{array}$ & Geologia & $\begin{array}{c}\text { Nível } \\
\text { Estático } \\
\text { (m) }\end{array}$ & $\begin{array}{c}\text { Índice de } \\
\text { Vulnerabilidade } \\
\text { "GOD" }\end{array}$ \\
\hline 260680 & 6628025 & 02184 & 380 & $\begin{array}{c}\text { Complexo Granítico- } \\
\text { Gnáissico }\end{array}$ & 3,00 & 0,43 Média \\
\hline 260720 & 6628000 & 02185 & 360 & $\begin{array}{c}\text { Complexo Granítico- } \\
\text { Gnáissico }\end{array}$ & 3,00 & 0,43 Média \\
\hline 261980 & 6625126 & 20715 & 385 & $\begin{array}{c}\text { Complexo Granítico- } \\
\text { Gnáissico }\end{array}$ & 2,00 & 0,14 Baixa \\
\hline 235253 & 6594764 & 20717 & 237 & $\begin{array}{l}\text { Formação Rio } \\
\text { Bonito }\end{array}$ & 3,00 & 0,45 Média \\
\hline 235296 & 6594815 & 20716 & 243 & $\begin{array}{l}\text { Formação Rio } \\
\text { Bonito }\end{array}$ & 18,00 & 0,40 Média \\
\hline 254788 & 6606400 & 20757 & 424 & $\begin{array}{c}\text { Complexo Granítico- } \\
\text { Gnáissico }\end{array}$ & 7,80 & 0,13 Baixa \\
\hline 258505 & 6614042 & 20758 & 407 & $\begin{array}{c}\text { Complexo Granítico- } \\
\text { Gnáissico }\end{array}$ & 70,00 & 0,10 Baixa \\
\hline 264391 & 6612773 & 20759 & 384 & $\begin{array}{c}\text { Complexo Granítico- } \\
\text { Gnáissico }\end{array}$ & 14,00 & 0,13 Baixa \\
\hline 260772 & 6627946 & 20760 & 370 & $\begin{array}{c}\text { Complexo Granítico- } \\
\text { Gnáissico }\end{array}$ & 3,00 & 0,14 Baixa \\
\hline 260668 & 6628031 & 20761 & 380 & $\begin{array}{c}\text { Complexo Granítico- } \\
\text { Gnáissico }\end{array}$ & 3,00 & 0,14 Baixa \\
\hline 269001 & 6616940 & 20762 & 155 & $\begin{array}{c}\text { Complexo Granítico- } \\
\text { Gnáissico }\end{array}$ & 3,00 & 0,16 Baixa \\
\hline
\end{tabular}




\begin{tabular}{|l|l|l|l|c|c|c|}
\hline 258760 & 6615918 & 20763 & 414 & $\begin{array}{c}\text { Complexo Granítico- } \\
\text { Gnáissico }\end{array}$ & 5,80 & 0,13 Baixa \\
\hline 284221 & 6614567 & 20764 & 88 & Grupo Guaritas & 8,00 & 0,40 Média \\
\hline 280106 & 6593251 & 20765 & 242 & $\begin{array}{c}\text { Complexo Granítico- } \\
\text { Gnáissico }\end{array}$ & 3,71 & 0,14 Baixa \\
\hline 273364 & 6613140 & 20766 & 147 & Formação Hilário & 9,00 & 0,08 Insignificante \\
\hline 264015 & 6638871 & 20767 & 170 & $\begin{array}{c}\text { Complexo Granítico- } \\
\text { Gnáissico }\end{array}$ & 6,00 & 0,13 Baixa \\
\hline 264370 & 6638761 & 20768 & 163 & Formação Hilário & 8,60 & 0,08 Insignificante \\
\hline 263921 & 6638834 & 20769 & 167 & Formação Hilário & 2,00 & 0,07 Insignificante \\
\hline 266979 & 6618706 & 20770 & 177 & $\begin{array}{c}\text { Complexo Granítico- } \\
\text { Gnáissico }\end{array}$ & 12,70 & 0,13 Baixa \\
\hline 267445 & 6618845 & 20771 & 161 & $\begin{array}{c}\text { Complexo Granítico- } \\
\text { Gnáissico }\end{array}$ & 6,00 & 0,13 Baixa \\
\hline 276148 & 6640954 & 21428 & 192 & Formação Palermo & 77,43 & 0,30 Média \\
\hline 277491 & 6618859 & 21445 & 175 & Grupo Santa Bárbara & 1,03 & 0,45 Média \\
\hline 257449 & 6633773 & 22738 & 227 & $\begin{array}{c}\text { Complexo Granítico- } \\
\text { Gnáissico }\end{array}$ & 6,00 & 0,13 Baixa \\
\hline 262254 & 6624142 & 22739 & 412 & $\begin{array}{c}\text { Complexo Granítico- } \\
\text { Gnáissico }\end{array}$ & 1,00 & 0,14 Baixa \\
\hline 265799 & 6640365 & 22740 & 122 & $\begin{array}{c}\text { Formação Palermo } \\
\text { Bonito }\end{array}$ & 45,00 & 0,35 Média \\
\hline 279768 & 6641133 & 23324 & 165 & $\begin{array}{c}\text { Formação. Rio } \\
0,35 \text { Média }\end{array}$ \\
\hline
\end{tabular}

Tabela 1 - Poços de abastecimento do município de Caçapava do Sul usados na análise (CPRM/SIAGAS).

A partir desses índices, foi gerado o Mapa de vulnerabilidade do município (Figura 2).

Pode-se observar os respectivos domínios apresentando áreas com grau de variação de Insignificante a Média, sendo:

a) Insignificante (11\%);

b) Média (35\%);

c) Baixa (54\%). 

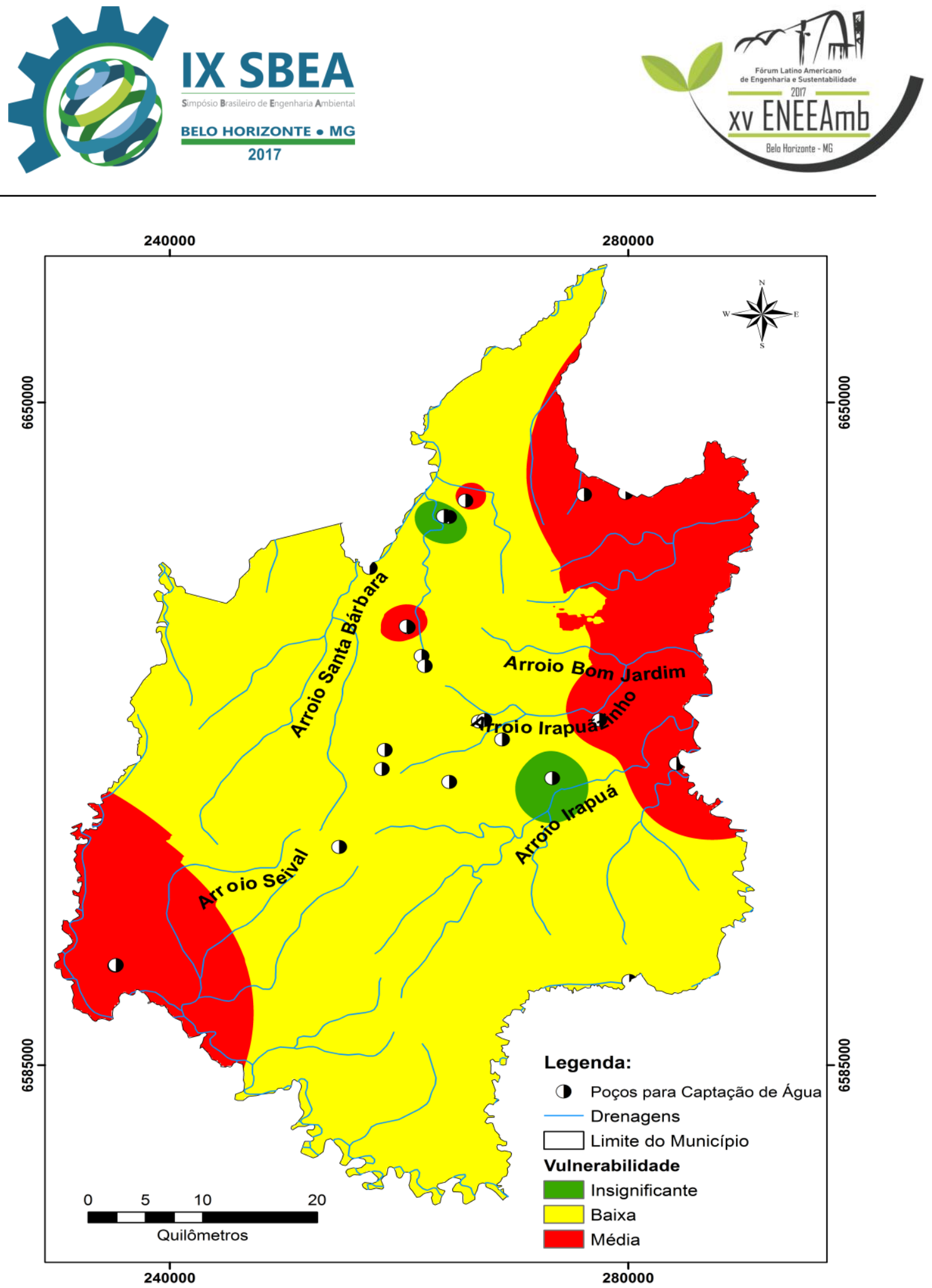

Figura 2 - Mapa vulnerabilidade do aquífero gerado, domínios e áreas com potencial suscetibilidade à contaminação.

A partir dos dados processados os valores dos níveis Estáticos e Dinâmicos permitiram a geração de uma superfície com visualização 3D (Figura 3) com distinção da camada solo/rocha e a direção do escoamento superficial dos fluidos. 

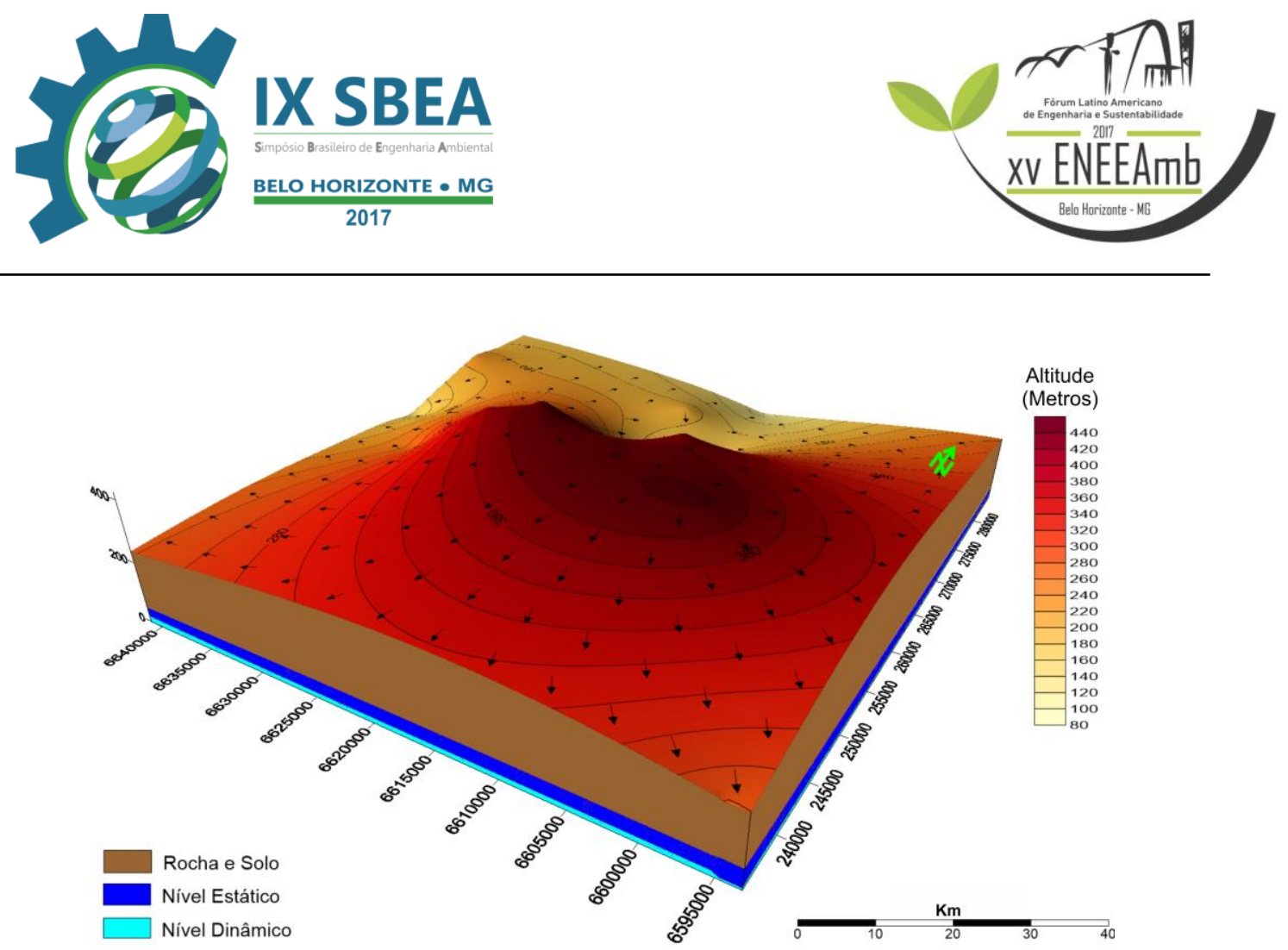

Figura 3 - Bloco diagrama com visualização em 3D entre o nível estático versus dinâmico em relação a superfície e linhas de direções preferenciais de fluxo (escoamento superficial).

A integração com os dados da FEPAM possibilitou a definição de domínios com atividades impactantes para o meio ambiente e aquíferos conforme abaixo descritas:

a) Agrossilvipastoril;

b) Mineração;

c) Infraestrutura e Transporte;

d) Industria e Saneamento.

Estes elementos foram definidos em quatro grandes grupos (Tabela 2) que foram georreferenciados e permitiram gerar o Mapa Integrado com Áreas Potenciais Poluidoras onde os resultados espacializados podem ser visualizados (Figura 4). A partir desse mapa, foi delimitado três grandes regiões com suas respectivas características:

- Região Nordeste - empresas de laticínios, estocadoras de grãos, cultivo agroindustrial e pequenos produtores;

- Região Central - indústria, empresas de mineração e alimentos;

- Região Sudoeste - pequenos agricultores e pecuaristas.

\begin{tabular}{|c|c|c|}
\hline Ramo do & Número de & Média do Potencial \\
Empreendimento & Empreendimentos & Poluidor \\
\hline
\end{tabular}



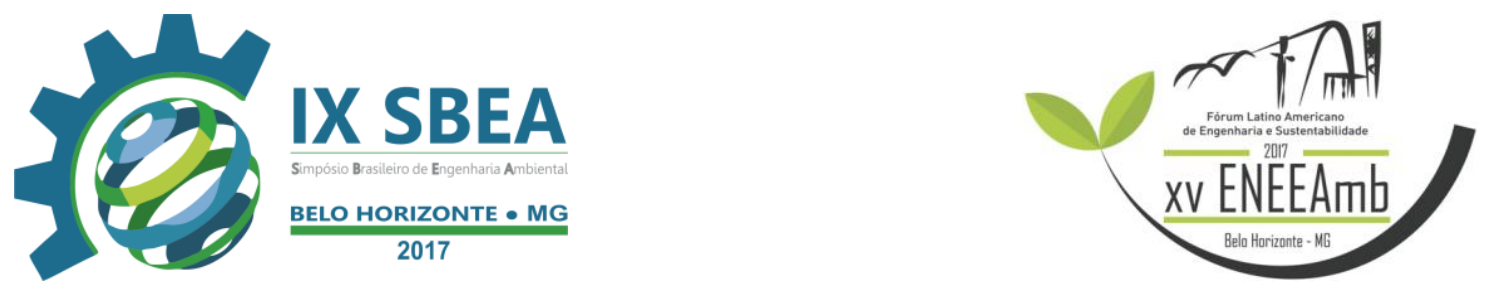

\begin{tabular}{|c|c|c|}
\hline Mineração & 33 & Médio \\
\hline Agrossilvipastoril & 66 & Alto \\
\hline Infraestrutura e Transporte & 61 & Médio \\
\hline Indústria e Saneamento & 425 & Alto \\
\hline
\end{tabular}

Tabela 2 - Quantidade e tipos de empreendimentos e seus respectivos Potenciais Poluidores.

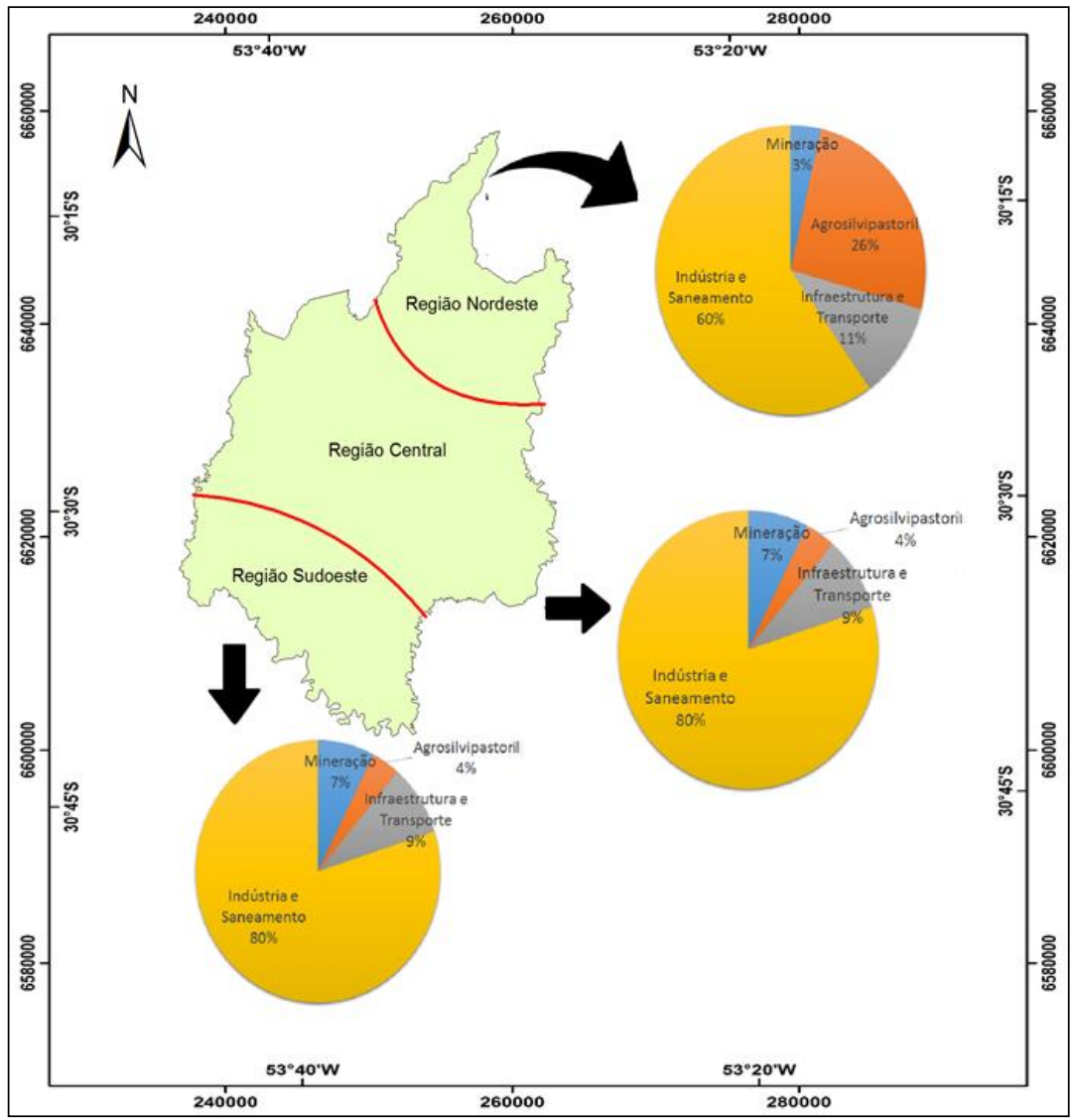

Figura 4 - Mapa Integrado com Áreas Potenciais Poluidoras dos principais empreendimentos do município.

\section{CONCLUSÕES E RECOMENDAÇÕES}

A elaboração do mapa da vulnerabilidade do aquífero à contaminação através do método GOD integrado aos dados pré-existentes do SIAGAS e FEPAM contribuiu para o refinamento e compreensão dos aquíferos no Escudo Cristalino do município de Caçapava do Sul. Foi possível identificar regiões mais susceptíveis a contaminação dos recursos hídricos subterrâneos, que integrados a informações estruturais, pedológicas e petrográficas visam 

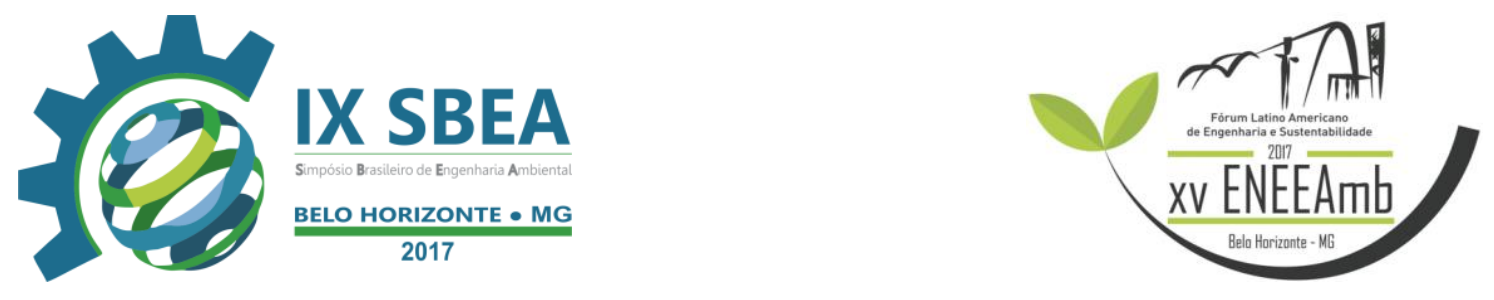

minimizar impactos ambientais e propiciar otimização na locação, perfuração e construção de poços tubulares.

Os poços com maiores riscos de contaminação situam-se na região nordeste e sudoeste do município, enquanto as áreas menos vulneráveis situam-se nas áreas centrais.

A visualização 3D com as linhas de fluxo do escoamento superficial e distinção da camada solo/rocha - Nível Estático/Dinâmico permite definir que os aquíferos com menor altitude estão menos susceptíveis a contaminação.

Por fim sugere-se um cadastramento respeitando a importância da inserção de todas as informações de poços tubulares do município pelo órgão expedidor, assim como monitoramento ambiental constante dos empreendimentos. Estes poços tubulares são usados, na sua maioria, para o abastecimento humano e, principalmente, nas indústrias do setor primário como a agricultura e pecuária.

\section{REFERÊNCIAS BIBLIOGRÁFICAS}

AMARAL, Luiz Augusto do et al. Água de consumo humano como fator de risco à saúde em propriedades rurais. Revista de Saúde Pública, p. 510-514, 2003.

FEPAM - Fundação Estadual de Proteção Ambiental - RS, dados de licenciamento ambiental, disponível em < www.fepam.rs.gov.br> Acesso em 27 de junho 2016.

FOSTER, Stephen SD; HIRATA, Ricardo César; ROCHA, Gerôncio Albuquerque. Riscos de Poluição de águas subterrâneas: uma proposta metodológica de avaliação regional. Águas Subterrâneas, 1987.

SELLER, L. E.; CANTER, Larry W. Summary of Selected Ground Water Quality Impact Assessment Methods. National Center for Ground Water Research, 1980.

TAVARES, Paulo Roberto Lacerda et al. Mapeamento da vulnerabilidade à contaminação das águas subterrâneas localizadas na Bacia Sedimentar do Araripe, Estado do Ceará, Brasil. Rem: Revista Escola de Minas, v. 62, n. 2, 2009. 